\title{
Investigation of an Outbreak of Fusarium Foot and Fruit Rot of Pumpkin Within the United States
}

\author{
Wade H. Elmer, The Connecticut Agricultural Experiment Station, P. O. Box 1106, New Haven 06504; Sarah F. \\ Covert, Warnell School of Forestry and Natural Resources, University of Georgia, Athens 30602; and Kerry \\ O'Donnell, Microbial Genomics Research Unit, National Center for Agricultural Utilization Research, United States \\ Department of Agriculture-Agricultural Research Service, Peoria, IL 61604
}

\begin{abstract}
Elmer, W. H., Covert, S. F., and O'Donnell, K. 2007. Investigation of an outbreak of Fusarium foot and fruit rot of pumpkin within the United States. Plant Dis. 91:1142-1146.

Isolates of two biologically and phylogenetically distinct species, referred to as Fusarium solani f. sp. cucurbitae race 1 (Fsc-1 = Nectria haematococca mating population I [MPI]) and F. solani f. sp. cucurbitae race $2(F s c-2=N$. haematococca mating population V [MPV]), were suspected of causing an outbreak of Fusarium foot and fruit rot of pumpkin during 2001 to 2003 in Connecticut, New York, Ohio, and Missouri. Both species affect the fruit, but Fsc-1 also affects the crown and causes a stem rot. In this study, 156 isolates from affected plants and from soil under diseased fruit that tentatively were identified morphologically as members of the $F$. solani species complex were assayed for pathogenicity on pumpkin seedlings and mature fruit. Results of the pathogenicity assay indicated that 81 of the isolates were $F s c-1$. The remaining 74 isolates were either nonpathogenic or only weakly pathogenic on the fruit. A subset of 53 test isolates from soil and plants, plus reference isolates of $F s c-1$ and $F s c-2$ and an isolate from wheat reported to cause a seedling rot on cucurbits, were characterized phylogenetically by sequencing a portion of the translation elongation factor $1-\alpha$ gene. A BLAST query of the FUSARIUM-ID database at Pennsylvania State University indicated that 42 of the 53 test isolates were $F s c-1$, whereas none were typed as $F s c$-2. A polymerase chain reaction assay for mating-type (MAT) idiomorph revealed that all of the $F s c-1$ isolates were MAT-1-2, suggesting that the pathogen may be strictly clonal in the affected fields. These findings provide convincing evidence that the Fusarium foot and fruit rot outbreaks were incited by Fsc-1.
\end{abstract}

Although members of the Fusarium solani species complex (FSSC) include many morphologically similar species, several phylogenetic studies have demonstrated that this large monophyletic group comprises over 30 phylogenetically distinct species distributed among three clades $(1,2,15,16)$. Several putative host-specific pathogens or formae speciales are nested within clade 3 , including two species that cause crown rots as well as lesions on Cucurbita fruit (8). The other 10 Fusaria reported as pathogens on Cucurbita spp. are associated primarily with fruit damage or wilt diseases $(8,25)$. The FSSC disease of cucurbit crowns and fruit, called Fusarium foot and fruit rot, first was reported in the United States in California in 1938 (21). When specificity to cucurbits was demonstrated, the pathogen was renamed Fusarium solani. f. sp. cucurbitae (Fsc-1) (22). Subsequently, in the late 1950s, Tousson and Snyder (24) isolated a second cucurbit pathogen at low frequencies that

Corresponding author: W. H. Elmer

E-mail: wade.elmer@po.state.ct.us

Accepted for publication 5 April 2007.

doi:10.1094/PDIS-91-9-1142

(C) 2007 The American Phytopathological Society affected only the fruit, which they named race 2 of $F$. solani f. sp. cucurbitae (Fsc2). Each so-called race later was shown to represent different heterothallic biological species, designated Nectria haematococca mating populations MPI and MPV, respectively (13). In addition to sexual incompatibility and different pathogenicity traits, Crowhurst et al. (6) found that $F s c$-1 (MPI) and $F s c-2$ (MPV) could be differentiated by random amplification of polymorphic DNA. It also has been shown that $F s c-1$ and $F s c-2$ represent phylogenetically distinct species with independent evolutionary origins (16).

Eight years after the first report, the Fusarium foot and fruit rot spread to New England, presumably on squash seed (11), where it continues to reappear sporadically. During the drought years of 200103, the disease caused major losses on

pumpkin farms scattered over four counties in Connecticut. In these outbreaks, fruit symptoms were common in all fields, but other plant tissues frequently were asymptomatic, leading to the initial presumption that $F s c-1$ and $F s c-2$ both were present. Simultaneous outbreaks affecting only the fruit also were observed in Missouri, Ohio, and New York (C. A Wyenandt, Rutgers University; L. Blackwell, Blackwell Family Produce, Salem, MO; and T. A. Zitter and M. McGrath, Cornell University, personal communication). The objective of this study was to determine which Fusaria were present in affected pumpkin fields in all four of these states during the 2001-03 outbreak of Fusarium foot and fruit rot. To do so, we used morphological comparisons, pathogenicity experiments, and molecular phylogenetics.

\section{MATERIALS AND METHODS}

Origin of isolates. The 156 isolates included in this study were obtained from crown or basal stems, fruit, and from soil proximal to affected fruit in Connecticut ( $n$ $=128)$, Missouri $(n=14)$, New York $(n=$ $9)$, and Ohio $(n=5)$ (Table 1). Soil, plants, or fruit were sampled from four sites in Connecticut: Cheshire, Gales Ferry, Roxbury, and Shelton. To obtain sterile isolates, tissue was surface disinfested with $0.053 \%$ sodium hypochlorite for $1 \mathrm{~min}$ followed by a sterile water rinse, and then the tissue was incubated on peptone pentachloronitrobenzene agar (PPA) (14) in the dark for 5 days at $20^{\circ} \mathrm{C}$. Soil isolates were obtained by removing one to two soil cores with an auger $(2.5 \mathrm{~cm}$ in diameter and 15 $\mathrm{cm}$ in depth) from underneath three affected pumpkin fruit per site. The soil samples from each site were bulked, dried, and passed through a 2-mm sieve. Three 1$\mathrm{g}$ sample aliquots per site were agitated in $100 \mathrm{ml}$ of sterile water and $0.1-\mathrm{ml}$ aliquots

Table 1. Speciation of field isolates based on pathogenicity on pumpkin seedlings and mature fruit

\begin{tabular}{lccc} 
& & \multicolumn{2}{c}{ Species $^{\mathbf{a}}$} \\
\cline { 3 - 4 } Environmental source & No. of isolates tested & $\boldsymbol{F s c} \mathbf{- 1}$ & $\boldsymbol{F s c}^{-2}$ \\
\hline Fruit & 96 & 73 & 0 \\
Plant stem & 13 & 8 & 0 \\
Soil & $47^{\mathrm{b}}$ & 0 & 0 \\
\hline
\end{tabular}

a Based solely on the disease reaction; Fusarium solani f. sp. cucurbitae race 1 (Fsc-1) isolates caused disease on pumpkin seedling tests and fruit; Fusarium solani f. sp. cucurbitae race 2 (Fsc-2) isolates caused disease only on fruit inoculations.

b Two soil isolates gave pathogenic reaction on pumpkin fruit. 
were spread onto PPA and incubated as described above. Single conidia arising from these colonies were subcultured onto carnation leaf agar (CLA) and potato dextrose agar (PDA) and held at 18 to $23^{\circ} \mathrm{C}$ under cool white and black fluorescent lights set for 12 -h photoperiods. Colonies tentatively were assigned to morphological species and then stored on silica gel (14). In addition, isolates previously identified as $F s c-1$ and $F s c-2$ were obtained from the Fusarium Research Center, Pennsylvania State University, University Park, or the Agricultural Research Service Culture Collection (NRRL) in Peoria, IL.

Table 2. Origin, pathogenicity, mating type (MAT), and identification of strains used in this study

\begin{tabular}{|c|c|c|c|c|c|c|c|}
\hline \multirow[b]{2}{*}{ NRRL no. ${ }^{b}$} & \multirow[b]{2}{*}{ Tissue or isolate code } & \multirow[b]{2}{*}{ Origin } & \multicolumn{2}{|c|}{ Pathogenicity $^{\mathbf{a}}$} & \multirow[b]{2}{*}{ Race $^{\mathrm{c}}$} & \multirow[b]{2}{*}{ MAT } & \multirow[b]{2}{*}{$E F-1 \alpha^{d}$} \\
\hline & & & Fruit & Seedling & & & \\
\hline 43315 & Fruit lesion & Glastonbury, CT & +++ & +++ & 1 & 2 & $F s c-1$ \\
\hline 43316 & Fruit lesion & Cheshire, CT & +++ & +++ & 1 & 2 & $F s c-1$ \\
\hline 43317 & Fruit lesion & Gales Ferry, CT & +++ & +++ & 1 & 2 & $F s c-1$ \\
\hline 43318 & Fruit lesion & Salem, MO & +++ & +++ & 1 & 2 & $F s c-1$ \\
\hline 43319 & Fruit lesion & Roxbury, CT & +++ & +++ & 1 & 2 & Fsc-1 \\
\hline 43320 & Fruit lesion & Long Island, NY & +++ & +++ & 1 & 2 & $F s c-1$ \\
\hline 43322 & Fruit lesion & Ohio & +++ & +++ & 1 & 2 & $F s c-1$ \\
\hline 43379 & Fruit lesion & Bethany, CT & +++ & ++ & 1 & 2 & $F s c-1$ \\
\hline 43381 & Fruit lesion & Gales Ferry, CT & +++ & +++ & 1 & 2 & $F s c-1$ \\
\hline 43382 & Fruit lesion & Gales Ferry, CT & ++ & +++ & 1 & 2 & Fsc-1 \\
\hline 43383 & Fruit lesion & Gales Ferry, CT & ++ & +++ & 1 & 2 & Fsc- 1 \\
\hline 43385 & Fruit lesion & Gales Ferry, CT & ++ & +++ & 1 & 2 & $F s c-1$ \\
\hline 43386 & Fruit lesion & Gales Ferry, CT & ++ & +++ & 1 & 2 & $F s c-1$ \\
\hline 43387 & Plant stem & Gales Ferry, CT & +++ & +++ & 1 & 2 & $F s c-1$ \\
\hline 43388 & Plant stem & Gales Ferry, CT & +++ & +++ & 1 & 2 & $F s c-1$ \\
\hline 43391 & Fruit lesion & Ohio & ++ & +++ & 1 & 2 & $F s c-1$ \\
\hline 43393 & Fruit lesion & Cheshire, CT & ++ & +++ & 1 & 2 & $F s c-1$ \\
\hline 43398 & Fruit lesion & Cheshire, CT & +++ & +++ & 1 & 2 & $F s c-1$ \\
\hline 43394 & Fruit lesion & Cheshire, CT & +++ & +++ & 1 & 2 & $F s c-1$ \\
\hline 43399 & Fruit lesion & Salem, MO & +++ & +++ & 1 & 2 & Fsc-1 \\
\hline 43400 & Fruit lesion & Salem, MO & +++ & +++ & 1 & 2 & $F s c-1$ \\
\hline 43401 & Fruit lesion & Salem, MO & ++ & +++ & 1 & 2 & Fsc-1 \\
\hline 43402 & Fruit lesion & Roxbury, CT & +++ & +++ & 1 & 2 & $F s c-1$ \\
\hline 43404 & Fruit lesion & Roxbury, CT & +++ & +++ & 1 & 2 & $F s c-1$ \\
\hline 43405 & Fruit lesion & Roxbury, CT & +++ & +++ & 1 & 2 & $F s c-1$ \\
\hline 43406 & Fruit lesion & Roxbury, CT & +++ & +++ & 1 & 2 & $F s c-1$ \\
\hline 43408 & Fruit lesion & Ohio & +++ & +++ & 1 & 2 & Fsc-1 \\
\hline 43409 & Fruit lesion & Ohio & +++ & +++ & 1 & 2 & $F s c-1$ \\
\hline 43410 & Fruit lesion & Glastonbury, CT & ++ & +++ & 1 & 2 & $F s c-1$ \\
\hline 43411 & Fruit lesion & Glastonbury, CT & ++ & +++ & 1 & 2 & $F s c-1$ \\
\hline 43412 & Fruit lesion & Glastonbury, CT & +++ & +++ & 1 & 2 & $F s c-1$ \\
\hline 43413 & Fruit lesion & Glastonbury, CT & +++ & +++ & 1 & 2 & Fsc-1 \\
\hline 43414 & Fruit lesion & Glastonbury, CT & +++ & +++ & 1 & 2 & $F s c-1$ \\
\hline 43417 & Fruit lesion & Ohio & +++ & +++ & 1 & 2 & $F s c-1$ \\
\hline 43418 & Plant stem & Shelton, CT & +++ & +++ & 1 & 2 & $F s c-1$ \\
\hline 43419 & Fruit lesion & Shelton, CT & +++ & +++ & 1 & 2 & $F s c-1$ \\
\hline 43420 & Fruit lesion & Shelton, CT & +++ & +++ & 1 & 2 & $F s c-1$ \\
\hline 43421 & Fruit lesion & Shelton, CT & +++ & +++ & 1 & 2 & $F s c-1$ \\
\hline 43422 & Fruit lesion & Shelton, CT & +++ & +++ & 1 & 2 & $F s c-1$ \\
\hline 43424 & Fruit lesion & Shelton, CT & +++ & +++ & 1 & 2 & $F s c-1$ \\
\hline 43425 & Plant Stem & Shelton, CT & +++ & +++ & 1 & 2 & $F s c-1$ \\
\hline 43426 & Fruit lesion & Long Island, NY & +++ & +++ & 1 & 2 & $F s c-1$ \\
\hline 43415 & Fruit lesion & California & - & - & - & - & $F s c-2^{\mathrm{e}}$ \\
\hline 43416 & Fruit lesion & California & - & - & - & - & $F s c-2$ \\
\hline 43321 & Fruit lesion & Gales Ferry, CT & - & - & - & - & FSSC clade 3 \\
\hline 43389 & Soil & Gales Ferry, CT & + & - & - & 1 & FSSC clade 3 \\
\hline 43390 & Soil & Gales Ferry, CT & + & - & - & 1 & FSSC clade 3 \\
\hline 43407 & Fruit lesion & Roxbury, CT & - & - & - & - & FSSC clade 3 \\
\hline 43384 & Fruit lesion & Gales Ferry, CT & - & - & - & - & Fusarium oxysporum \\
\hline 43423 & Fruit lesion & Shelton, CT & - & - & - & - & Fusarium oxysporum \\
\hline 43380 & Fruit lesion & Hamden, CT & + & - & - & - & Fusarium sp. ${ }^{\mathrm{f}}$ \\
\hline 43392 & Fruit lesion & Cheshire, CT & + & - & - & - & $F . c f$. dimerum \\
\hline 43395 & Fruit lesion & Cheshire, CT & + & - & - & - & F. cf. equiseti \\
\hline 43396 & Fruit lesion & Cheshire, CT & - & - & - & - & F.cf. dimerum \\
\hline 43397 & Fruit lesion & Cheshire, CT & - & - & - & - & F.cf. dimerum \\
\hline 43323 & Wheat stem & India & - & - & - & $1 \& 2$ & Neocosmospora vasinfecta \\
\hline
\end{tabular}

a Pathogenicity based seedling and fruit reactions: $+=$ weak reaction (one seedling or fruit), $++=$ moderation reaction (two to four seedlings or fruit), and $+++=$ strong reaction (five to six seedlings or fruit).

b Depository number for the United States Department of Agriculture-Agricultural Research Service culture collection, Peoria, IL.

c Fusarium solani f. sp. cucurbitae race 1 isolates (Fsc-1) were pathogenic on seedlings and fruit, whereas $F$. solani f. sp. cucurbitae race 2 isolates (Fsc-2) were pathogenic only on fruit.

${ }^{d}$ EF-1 $\alpha$-based identification; partial sequences were submitted to a BLAST query of the FUSARIUM-ID database at Pennsylvania State University (10). FSSC $=F$. solani species complex and $\mathrm{cf}=$ compared with.

e NRRL 43415 = FRC S-202; NRRL 43416 = FRC S-203, (FRC = Fusarium Research Center Pennsylvania State University, State College, PA).

f Gibberella fujikuroi species complex.

g N. vasinfecta $=$ homothallic, microconidial species reported as pathogenic on cucurbit seedlings (FRC S-0693) (20). 
Pathogenicity tests. Each isolate was cultured on potato-carrot agar (7) and incubated as described above. Conidia were harvested from the plates with two separate washes of $10 \mathrm{ml}$ of distilled water, and then the suspension was diluted to $1 \times 10^{6}$ conidia/ml. Each isolate suspension $(25$ $\mathrm{ml}$ ) was poured around the stems of three 10-day-old pumpkin seedlings (cv. Howden; Harris Seed Co., Rochester, NY) that had been planted in Promix BX potting mix (Premier Brand Co., New Rochelle, NY). After 10 to 14 days in the greenhouse (day and night temperatures of 22 and $16^{\circ} \mathrm{C}$, respectively), seedlings were examined for symptoms of collapsed stems and damping off and scored as nonpathogenic or pathogenic. Isolates were retested on three more seedlings for a total of six seedlings and scored as weakly, moderately, or highly pathogenic by whether or not they caused symptoms on one, two to four, or more than four seedlings, respectively.

Mature, blemish-free pumpkin fruit (cv. Howden) were collected from field plots in 2002 from Lockwood Farm, Hamden, CT, where no Fusarium fruit and crown rot had been observed. Fruit were rinsed with tap water, then with $0.027 \%$ sodium hypochlorite, followed by another tap-water wash, and allowed to dry on greenhouse benches. A sterile scalpel was used to puncture 8 to 10 small holes $(0.5 \mathrm{~cm}$ deep) on the shoulder and sides of each fruit. Approximately $50 \mu$ of $1 \times 10^{6}$ conidia $/ \mathrm{ml}$ of each test isolate was injected into the wound with a syringe, using inocula prepared as described for the seedling tests. Each fruit was inoculated with seven different test isolates and a negative control (distilled water). Each isolate was tested on three separate fruit, but arranged so that the same seven isolates were not tested together on a fruit more than once. Inoculated fruit were randomly arranged on greenhouse benches (day and night temperatures of 22 and $16^{\circ} \mathrm{C}$, respectively) and incubated for 7 to 10 days, at which time they were scored as pathogenic if an expanding sunken lesion developed that later sporulated. The fungus was reisolated onto CLA and confirmed to have macroconidia and microconidia typical of isolates of $F$. solani. f. sp. cucurbitae. Isolates were retested on three more mature fruit harvested in 2003 for a total of six fruit and scored as weakly, moderately, or highly pathogenic by whether or not they caused lesions resembling $F s c$ - 1 on one, two to four, or more than four fruit, respectively.

Molecular biology. In all, 56 representative isolates from different locales and niches (soil, stems, or fruit) were further characterized phylogenetically by sequencing a partial fragment of the translation elongation factor gene $(\mathrm{EF}-1 \alpha)$. All 56 isolates sequenced in this study (Table 2) have been deposited in the Agricultural Research Service (NRRL) Culture Collection, National Center for Agricultural
Utilization Research, Peoria, IL, where they are stored cryogenically at $-175^{\circ} \mathrm{C}$. All isolates were grown in yeast-malt broth for 2 to 3 days at $24^{\circ} \mathrm{C}$, after which mycelium was harvested over a Büchner funnel and freeze dried prior to the DNA extraction step (17).

Total genomic DNA was prepared by a hexadecyltrimethyl-ammonium bromide (Sigma-Aldrich, St. Louis) protocol as previously described (18). Polymerase chain reaction (PCR) amplification of a partial fragment of EF- $1 \alpha$ was performed with primers EF-1 and EF-2, and PCR reagents and cycling conditions as described in O'Donnell et al. (19). After the amplicons were purified using Montage $\mathrm{PCR}_{96}$ cleanup filter plates (Millipore, Billerica, MA), they were sequenced with one forward (EF-3> GTAAGGAGGASA AGACTCACC) and one reverse sequencing primer (EF-22> AGGAACCCTTAC CGAGCTC). All sequencing reactions used the Applied Biosystems (ABI, Foster City, CA) Big Dye version 3.1 chemistry, an ABI 9700 thermocycler, and the following cycling parameters: $96^{\circ} \mathrm{C}$ for $15 \mathrm{~s} ; 40$ cycles of $96^{\circ} \mathrm{C}$ for $15 \mathrm{~s}, 50^{\circ} \mathrm{C}$ for $10 \mathrm{~s}$, and $60^{\circ} \mathrm{C}$ for $4 \mathrm{~min}$; and ending in a $4^{\circ} \mathrm{C}$ soak. Once sequencing reactions were purified via an ethanol-ammonium acetate precipitation step, they were resuspended in ABI Hi-Dye formamide and run on an automated ABI-Hitachi 3730 capillary sequencer (Tokyo). Chromatograms were edited with Sequencher (version 4.1.2; Gene Codes, Ann Arbor, MI). All of the sequence data have been deposited in GenBank under accession numbers DQ986151 to DQ986199.

Phylogenetic analysis and DNA-based identifications. Phylogenetic analysis of the aligned EF-1 $\alpha$ gene sequences was conducted with PAUP (version 4.0b10; Sinauer Associates Inc., Sunderland, MA; 23). Unweighted parsimony analysis was performed with the heuristic search option and 1,000 random addition sequences with the MULPARS function on and with tree bisection-reconnection branch swapping. Clade stability was assessed by 1,000 parsimony bootstrap pseudoreplicates of the data.

Mating-type idiomorph PCR assay. Genomic DNA was isolated from 84 field isolates as described above. Degenerate primers amplifying a 286-bp amplicon from the mating type (MAT) idiomorph MAT1-1 (M1F = GCCCTCTKAAYGCCT TYATGG; M1R = GGMSGGWTCAAYCATGYKCAT) and an approximately 1-kb base-pair amplicon from MAT idiomorph MAT1-2 (M2F = GGGAATCTRARAAAG RTACGTAC; M2R = CGAGGKCGGTAC TGGTAGTCGGG) were designed after aligning MAT gene sequences from $F$. verticillioides, $F$. oxysporum, $F$. circinatum (GenBank accession numbers AF100925, AF100926, AB011379, AB011378, AY219876, and AY219874), and $N$. haematococca MPVI (C. Wasmann and H. D. VanEtten, unpublished). PCR reactions (25 $\mu \mathrm{l}$ total volume) included $1 \mu \mathrm{l}$ of genomic DNA, $2 \mathrm{mM} \mathrm{MgCl}_{2}, 0.2 \mathrm{mM}$ each dNTP, $1.2 \mu \mathrm{M}$ each primer, and 1 unit thermostable DNA polymerase (Qiagen Inc., Valencia, CA). The following cycling parameters were used: $94^{\circ} \mathrm{C}$ for $3 \mathrm{~min}$, followed by 35 cycles of $94^{\circ} \mathrm{C}$ for $45 \mathrm{~s}$, $45^{\circ} \mathrm{C}$ for $30 \mathrm{~s}$, and $72^{\circ} \mathrm{C}$ for $90 \mathrm{~s}$. MAT PCR products from field isolates and $F s c$ - 1 and $F s c$-2 tester strains were size fractionated on a $1 \%$ agarose gel using a 50 - to 2,000-bp AmpliSize Molecular Ruler (BioRad Laboratories, Hercules, CA).

\section{RESULTS}

Pathogenicity experiment. Isolates identified as the morphospecies $F$. solani were obtained from symptomatic tissues and from soil that was sampled under symptomatic fruit. Of the 156 isolates tested, slightly more than half $(52 \%)$ were pathogenic and caused symptoms on both seedlings and mature fruit (Table 1). Inoculated seedlings often rotted at the crown and damped off whereas fruit lesions began as a slow, depressed lesion that expanded as sporodochia developed in the center of the lesion. Thus, all pathogens were typed as $F s c$-1. Only two soil isolates (NRRL 43389 and NRRL 43390) were scored as weakly pathogenic to pumpkin fruit; however, these isolates were phylogenetically distinct from $F s c-2$. Although an $F s c-1$ isolate from South Africa was avirulent in our trials, along with three Fusarium Research Center (FRC) isolates of Fsc-2 from California, NRRL strains 22153 and 22165 of $F s c$-1, were pathogenic on seedlings and fruit. Most isolates scored as nonpathogenic to pumpkin could be differentiated from the pathogens by colony morphology on PDA but not by conidial morphology on CLA. Overall, the soil isolates had higher radial growth rates and lacked pigmentation compared with the $F s c-1$ pathogens, which grew more slowly and had darker mycelium (data not shown). With the exception of NRRL 43389 and 43390 , there was no case where soil isolates were pathogenic on seedlings or fruit despite their isolation only centimeters away from symptomatic fruit.

Phylogenetics. Unweighted parsimony analysis of the aligned translation EF gene dataset revealed that nine unique EF-1 $\alpha$ haplotypes were represented among 56 isolates. To facilitate the identification of these isolates, one exemplar of each unique haplotype was submitted to a BLAST search of the FUSARIUM-ID database at Pennsylvania State University (10). All of the isolates that were highly pathogenic to pumpkin seed or fruit $(n=42)$ represented $F s c$-1. Eight isolates representing six unique EF-1 $\alpha$ haplotypes were determined by the BLAST query to not be members of the FSSC, yet four of these isolates gave weak reactions on pumpkin fruit (Table 2). 
These eight non-FSSC isolates were excluded from all subsequent phylogenetic analyses. Parsimony analysis of the EF- $1 \alpha$ dataset, which consisted of 721 nucleotide characters, of which 51 were cladistically informative, indicated that four phylogenetically distinct species within clade 3 of the FSSC were represented in this collection (Fig. 1). These four species included $F s c$-1, the two FRC $F s c-2$ tester strains (NRRL 43415 and 43416), Neocosmospora vasinfecta E. F. Sm. (1899) (teleomorph of an unnamed microconidial Fusarium sp. within the FSSC), and an unnamed Fusarium sp. that shares an identical EF- $1 \alpha$ haplotype with isolates of haplotype 78 of haplotype class 9 (15). This latter taxon is pathogenic to Lisianthus spp. in Ecuador and also is known to cause keratitis in horse and humans (15). Two isolates of this species were weakly pathogenic to pumpkin fruit (NRRL 43389 and NRRL 43390).

PCR screen for MAT idiomorph. Of the 83 FSSC isolates assayed for MAT idiomorph, 55 were typed as MAT1-2 (approximately 1-kb amplicon) and 5 nonpathogenic isolates were MAT1-1 (approximately $0.29-\mathrm{kb}$ amplicon). All of the remaining isolates could not be typed for MAT because the amplicons produced did not match the size of either idiomorph based on reference amplicons from known isolates of $F s c$ - 1 and $F s c-2$.

\section{DISCUSSION}

Of the 156 pumpkin field isolates obtained from soil and from symptomatic plants and fruit, roughly half were pathogenic on both seedlings and fruit. All isolates that were strongly pathogenic were identified phylogenetically as $F s c-1$, confirming that this species was responsible for the recent outbreak on pumpkin. Although a weak pathogenic response was observed with two soil isolates (NRRL 43389 and NRRL 43390), no evidence was found that any isolate belonged to Fsc-2. The inability of the remaining 45 soil isolates to cause disease on pumpkin may suggest that the infections were not due to the fruit having contact with the soil. The pathogen may have gained entry into the field via wind, rain splash, or contaminated seed or might have been introduced on insects or farm machinery. However, if introduced on seed, it is not clear why all plants in the field would remain asymptomatic until the fruit lesions appeared whereas, in other affected fields cropped to the same cultivars, pumpkin fruit would show crown collapse and death. Perhaps certain environmental conditions allow for asymptomatic colonization of the plant until fruit begin to develop, at which time symptoms emerge exclusively on fruit. The inability of the race 2 isolates (NRRL 43415 and NRRL 43416) to incite fruit lesions may have been due to a loss of pathogenicity which is not uncommon for
Fusarium isolates that have been in storage for extended periods of time.

It was interesting that, among the isolates representing the eight unique EF- $1 \alpha$ haplotypes determined by the BLAST query to not be members of the FSSC, that three of these gave weak reactions on pumpkin fruit. Of these, $F$. $c f$. dimerum, and $F$. c f. equiseti may belong to groups capable of weak pathogenicity on pumpkin. Previous studies have suggested that other related morphospecies may be pathogenic to pumpkin $(4,8)$ and other crops (12). Elmer (4) reported that other species of Fusarium occasionally could cause fruit lesions on pumpkin fruit. Because cracks develop in the rind of devel- oping fruit, it is not surprising that opportunistic species of Fusarium could gain entry and incite a mild lesion. These reactions could be misconstrued as evidence for $F s c$-2. In this connection, the value of molecular genotyping to correctly determine pathogen identification is evident in the present study. Moreover, the number of misidentified isolates may be significant when researchers report a low percentage of isolates that cause only fruit lesions. For example, Boughalleb et al. (3) reported that both $F s c-1$ and $F s c-2$ caused a crown, foot, and fruit rot disease of watermelon. Based on pathogenicity tests on watermelon seedlings and muskmelon fruit, they found that $93 \%$ of the isolates were identi-

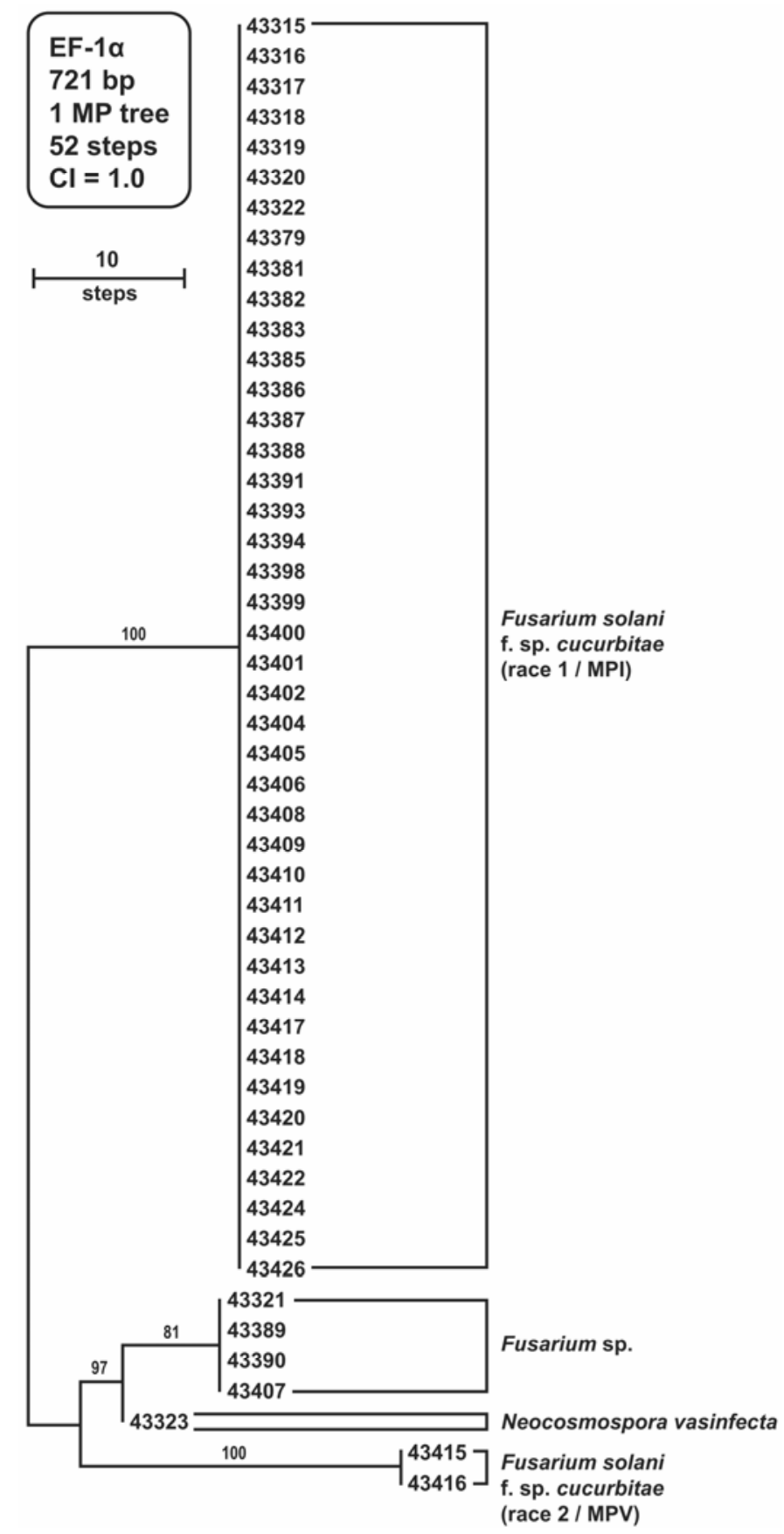

Fig. 1. Most parsinomous trees of 46 isolates within clade 3 of the Fusarium solani species complex based on sequences of the elongation factor $1-\alpha(E F 1-\alpha)$. 
fied as $F s c$ - 1 whereas only $4 \%$ were $F s c-2$ (3\% were not pathogenic). It would be informative to have molecular genotyping performed so another means of confirmation could be available to distinguish isolates of these two species from opportunistic fusarial pathogens.

Through the use of a PCR assay for MAT idiomorphs, we were able to demonstrate that only MAT1-2 isolates were involved in the current outbreak of Fusarium foot and fruit rot of pumpkin, suggesting that the reproductive mode of this pathogen may be strictly clonal. Similarly, only one mating-type of Nectria haematococca MPVI (anamorph F. solani f. sp. pisi) is typically found in a locale (9), and all U.S. isolates of $F$. virguliforme (FSSC clade 2; causative agent of soybean sudden death syndrome) appear to be of a single mating type (5), raising the possibility that clonally driven pathogen outbreaks may be common among the FSSC.

\section{ACKNOWLEDGMENTS}

We thank B. O'Dowd and J. Bravo for technical and field assistance; A. Strom for generating all of the DNA sequence data; D. Fraser for the tree figure; H. VanEtten for fertile isolates of MPVI; F. Ferrandino for supplying healthy pumpkin; and $\mathrm{M}$. McGrath, T. Zitter, A. Wyenandt, and L. Blackwell for providing isolates or diseased pumpkin fruit.

\section{LITERATURE CITED}

1. Aoki, T., O'Donnell, K., Homma, Y., and Lattanzi, A. R. 2003. Sudden death syndrome of soybean is caused by two morphologically and phylogenetically distinct species within the Fusarium solani species complex, F. virguliforme in North America and F. tucumaniae in South America. Mycologia 95:660-684.

2. Aoki, T., O'Donnell, K., and Scandiani, M. 2005. Sudden death syndrome of soybean in South America is caused by four species of Fusarium: Fusarium brasiliense sp. nov., F. cuneirostrum sp. nov., $F$. tucumaniae and $F$. virguliforme. Mycoscience 46:162-183.

3. Boughalleb, N., Armengol, J., and El Mahjoub, M. 2005. Detection of races 1 and 2 of Fusarium solani $\mathrm{f}$. sp. cucurbitae and their distribution in watermelon fields in Tunisia. J. Phytopathol. 153:162.

4. Correll, J. C., Mitchell, J. K., and Andersen, C. R. 1991. Fruit rot of pumpkin in Arkansas caused by Fusarium equiseti. Plant Dis. 75:751.

5. Covert, S. F., Aoki, T., O’Donnell, K., Starkey, D., Holliday, A., Geiser, D. M., Cheung, F., Town, C., Strom, A., Juba, J., Scandiani, M., and Yang, X. B. Sexual reproduction in the soybean sudden death syndrome pathogen Fusarium tucumaniae. Fungal Genet. Biol. In press.

6. Crowhurst, R. N., Hawthorne, B. T., Rikkerink, E. H. A., and Templeton, M. D. 1991. Differentiation of Fusarium solani f. sp. cucurbitae races 1 and 2 by random amplification of polymorphic DNA. Curr. Genet. 20:391-396.

7. Dhingra, O. D., and Sinclair, J. B. 1985. Basic Plant Pathology Methods. CRC Press, Inc., Boca Raton, FL.

8. Elmer, W. H. 1996. Fusarium fruit rot of pumpkins in Connecticut. Plant Dis. 80:131135.

9. Funnell, D. L., Matthews, P. S., and VanEtten, H. D. 2001. Breeding for highly fertile isolates of Nectria haematococca MPVI that are highly virulent on pea in planta selection for virulent recombinants. Phytopathology 91:92-101.

10. Geiser, D. M., del Mar Jiménez-Gasco, M., Kang, S., Makalowska, I., Veeraraghavan, N., Ward, T. J., Zhang, N., Kuldau, G. A., and O'Donnell, K. 2004. FUSARIUM-ID v.1.0: A DNA sequence database for identifying Fusarium. Eur. J. Plant Pathol. 110:473-479.

11. Gries, G. A. 1946. Physiology of Fusarium root rot of squash. Conn. Agric. Exp. Stn. Bull. 500 .

12. Jiménez, M., Logrieco, A., and Bottalico, A. 1993. Occurrence and pathogenicity of Fusarium species in banana fruits. J. Phytopathol. 137:214-220.

13. Matuo, T., and Snyder, W. C. 1973. Use of morphology and mating populations in the identification of formae speciales in Fusarium solani. Phytopathology 63:562-565.

14. Nelson, P. E., Toussoun, T. A., and Marassas, W. F. O. 1983. Fusarium species: An illustrated Manual for Identification. The Pennsylvania State University Press, University Park.

15. Ning, Z., O'Donnell, K., Sutton, D. A., Nalim, F. A., Summerbell, R. C., Padhye, A. A., and Geiser, D. M. 2006. Members of the Fusarium solani species complex that cause infections in both humans and plants are common in the environment. J. Clin. Microbiol. 44:2186-2190.

16. O'Donnell, K. 2000. Molecular phylogeny of the Nectria haematococca-Fusarium solani species complex. Mycologia 92:919-938.

17. O'Donnell, K., and Cigelnik, E. 1997. Two divergent intragenomic rDNA ITS2 types within a monophyletic lineage of the fungus Fusarium are nonorthologous. Mol. Phylogenet. Evol. 7:103-116.

18. O'Donnell, K., Cigelnik, E., and Nirenberg, H 1998a. Molecular systematics and phylogeography of the Gibberella fujikuroi species complex. Mycologia 90:465-493.

19. O’Donnell, K., Kistler, H. C., Cigelnik, E., and Ploetz, R.C. 1998b. Multiple evolutionary origins of the fungus causing Panama disease of banana: concordant evidence from nuclear and mitochondrial gene genealogies. Proc. Natl. Acad. Sci. USA 95:2044-2049.

20. Smith, E. F. 1899. Wilt disease of cotton watermelon, and cowpea (Neocosmospora nov. gen.). U. S. Dep. Agric. Bull 17:1-54.

21. Snyder, W. C. 1938. A Fusarium foot rot of cucurbita. (Abstr.) Phytopathology 28:19.

22. Snyder, W. C., and Hansen, H. N. 1941. The species concepts in Fusarium with reference of section Martiella. Am. J. Bot. 28:738-742.

23. Swofford, D. L. 2002. PAUP*. Phylogenetic Analysis Using Parsimony (*and other methods). Version 4.0b10. Sinauer Associates, Sunderland, MA.

24. Tousson, T. A., and Snyder, W. C. 1961. The pathogenicity, distribution, and control of two races of Fusarium (Hypomyces) solani f. sp. cucurbitae. Phytopathology 51:17-22.

25. Zitter, T. A., Hopkins, D. L., and Thomas, C. E. 1996. Compendium of Cucurbit Diseases. American Phytopathological Society Press, St Paul, MN. 